Author: KUDRYAVTSEV Pavel Gennadievich, Professor, D.Sc., Leading Researcher Polymate Israel Research Center (Israel), Academician of International Academy of Sciences for Ecology and Human Safety and Russian Academy of Natural Sciences, Author of 207 scientific works, including 4 monographs, has 34 inventions. He was awarded the M.V.Lomonosov medal, Commander of the Order «The Star of the Scientist» and was awarded the honorary title «Honored Worker of Science», awarded the medal of P.A.Stolypin, and honorable diamond sign of the Chamber of Commerce and Industry of the Russian Federation. Polymate Ltd. - Israel Research Center, POBox 73, Migdal HaEmek 10550, Israel, e-mail: pgkudr89@gmail.com;

Author: KUDRYAVTSEV Nikolai Pavlovich, Chief technologist Polymate - Israel Nanotechnology Research Center (Israel). Author of 11 scientific works, has 4 patents. Diploma of Perm national research polytechnic university of Fuel and Natural Energy Carriers; Passed internship at the University Friedrich-Alexander Erlangen and Nurnberg (Germany): Physico-chemical basis of separation processes. POBox 73, Migdal HaEmek, Polymate Ltd. - Israel Nanotechnology Research Center, 2320001, Israel, e-mail:koudryavtsev@yahoo.com;

Author: FIGOVSKY Oleg Lvovich, Professor, Full Member of European Academy of Sciences, Foreign Member of REA and RAASN, Editor-in-Chief of Journals SITA (Israel), OCJ and ICMS (USA), Director for Research and Development Polymate - Israel Research Center (Israel) and Nanotech Industries Inc., (USA); Chairman of the UNESCO chair «Green Chemistry»; President of Israel Association of Inventors; Laureate of the Golden Angel Prize, Commander of the Order «Engineering glory» (Russia) and «Leading Intellectuals of the World» (USA). Polymate Ltd. - Israel Research Center, POBox 73, Migdal HaEmek 10550, e-mail: figovsky@gmail.com

\title{
THE SOLUBLE ALUMINUM COMPOUNDS AND NANOCOMPOSITE MATERIALS BASED ON THEM. PART I
}

\section{ExTENDED Abstract:}

Simple aluminum compounds are precursors for all processes for the production of nanocomposite materials based on aluminum oxides. The present work analyzes the state of $\mathrm{Al}^{3+}$ aluminum ions in aqueous solutions. The state of $\mathrm{Al}^{3+}$ ions in aqueous solutions determines the mechanism and structure of the produced nanocomposites. The analysis of phase transformations in systems of aluminum salts, hydrated oxides and oxides is carried out. The main conditions to obtain final materials are determined on the basis on these data. An analysis of various methods used to prepare colloidal solutions of hydrated aluminum oxides has been performed. Such solutions are the main precursors in the production of nanocomposite materials based on aluminum oxides. The processes of obtaining alumina-sol by precipitation-peptization method which is one of the main methods were investigated. For the synthesis of alumina-sol, the possibilities of using 
ion exchange methods and controlled hydrolysis of aluminum compounds have also been considered. Analysis of the silica-sol and alumina-sol interaction processes was conducted to obtain a mixed oxide material in the system $\mathrm{SiO}_{2}-\mathrm{Al}_{2} \mathrm{O}_{3}$. The possibility of applying homogeneous precipitation of hydrated alumina to prepare nanocomposites based on aluminum oxide has been studied.

Keywords: alumina-sol; aluminum aquacomplexes; aluminum hydroxocomplexes; aluminum alkoxides; Hydrolysis of aluminum compounds; Hydrated aluminum oxides; boehmite; pseudoboehmite; hydrargillite; alumina-silica-sol; homogeneous precipitation.

MACHINE-READABLE INFORMATION ON CC-LICENSES (HTML-CODE) IN METADATA OF THE PAPER

<a rel="license" href="http://creativecommons.org/licenses/by/4.0/" $><$ img alt="Creative Commons License" style="borderwidth:0" src="https://i.creativecommons.org/l/by/4.0/88x31.png" $/></ a><$ br $/><$ span xmlns:dct="http://purl. org/dc/terms/" href="http://purl.org/dc/dcmitype/Text" property="dct:title" rel="dct:type" $>$ The soluble aluminum compounds and nanocomposite materials based on them. Part I. </span $>$ by <a xmlns:cc="http://creativecommons.org/ ns\#" href="Nanotehnologii v stroitel'stve = Nanotechnologies in Construction. 2018, Vol. 10, no. 1, pp. 37-62. DOI: dx.doi. org/10.15828/2075-8545-2018-10-1-37-62" property="cc:attributionName" rel="cc:attributionURL">Kudryavtsev P.G., Kudryavtsev N.P., Figovsky O.L. </a > is licensed under a $<$ a rel="license" href="http://creativecommons.org/licenses/ by/4.0/" $>$ Creative Commons Attribution 4.0 International License $</ \mathrm{a}>$. $<$ br $/>$ Based on a work at $<$ a xmlns:dct="http:// purl.org/dc/terms/" href=" http://nanobuild.ru/en_EN/nanobuild-1-2018/"rel="dct:source"> http://nanobuild.ru/ en_EN/nanobuild-1-2018/ $</ \mathrm{a}>$. $<$ br $/>$ Permissions beyond the scope of this license may be available at $<$ a xmlns:cc="http: $/ /$ creativecommons.org/ns \#" href="pgkudr89@gmail.com"rel="cc:morePermissions">pgkudr89@gmail.com</a>.

\section{DeAR COLLEAGUEs!}

THE REFERENCE TO THIS PAPER HAS THE FOLLOWING CITATION FORMAT:

Kudryavtsev P.G., Kudryavtsev N.P., Figovsky O.L. The soluble aluminum compounds and nanocomposite materials based on them. Part I. Nanotehnologii v stroitel'stve $=$ Nanotechnologies in Construction. 2018, Vol. 10, no. 1, pp. 37-62. DOI: dx.doi.org/10.15828/2075-8545-2018-10-1-37-62. (In Russian).

The part 2 and part 3 of the paper by Kudryavtsev P.G., Kudryavtsev N.P., Figovsky O.L. "The soluble aluminum compounds and nanocomposite materials based on them" will be published in the issue 2/2018 and 3/2018 in the Internet-Journal "Nanotechnologies in Construction".

The references for the part 1, part 2 and part 3 of the paper by Kudryavtsev P.G., Kudryavtsev N.P., Figovsky O.L. "The soluble aluminum compounds and nanocomposite materials based on them" will be also published in the issue 3/2018 in the Internet-Journal "Nanotechnologies in Construction". 
УДК 69.001.5+ 696.1

Автор: КУДРЯВЦЕВ Павел Геннадьевич, проф., D.Sc., вед. Научн.сотрудник Polymate - Israel Research Center (Израиль), действительный член (академик) МАНЭБ и РАЕН, автор 207 научных работ, в том числе 4 монографий, имеет 34 изобретения, награжден медалью им. М.В. Ломоносова, кавалер ордена «Звезда Ученого», удостоен почетного звания «Заслуженный деятель науки», награжден медалью П.А. Столыпина и почетным бриллиантовым знаком Торгово-промышленной палаты РФ; POBox 73, Migdal HaEmek, Polymate Ltd. - Israel Research Center, 10550, Израиль, e-mail: pgkudr89@gmail.com;

Автор: КУДРЯВЦЕВ Николай Павлович, главн. технолог Polymate - Israel Research Center (Израиль), автор 11 научных работ, имеет 3 патента; POBox 73, Migdal HaEmek, Polymate Ltd. Israel Nanotechnology Research Center, 2320001, Израиль, e-mail: nikkudr@yahoo.com;

Автор: ФИГОВСКИЙ Олег Львович, профессор, действительный член Европейской академии наук, иностранный член РИА и PAACH, главный редактор журналов SITA, OCJ и RPCS, директор по науке и развитию Polymate - Israel Research Center (Израиль) и Nanotech Industries Inc. (USA), зав. кафедрой ЮНЕСКО «Зелёная химия», президент Израильской ассоциации изобретателей, лауреат Golden Angel Prize, кавалер орденов «Инженерная слава» (Россия) и «Leading Intellectuals of the World» (USA); POBox 73, Migdal HaEmek, Polymate Ltd. - Israel Research Center, 10550, Израиль, e-mail: figovsky@gmail.com

\section{РАСТВОРИМЫЕ СОЕДИНЕНИЯ АЛЮМИНИЯ И НАНОКОМПОЗИТНЫЕ МАТЕРИАЛЫ НА ИХ ОСНОВЕ. ЧАСТЬ I}

АННОТАЦИЯ К СТАТЬЕ (АВТОРСКОЕ РЕЗЮмЕ, РЕФЕРАТ):

Настоящая статья посвящена применению растворимых соединений алюминия для получения нанокомпозитных материалов. Проведен анализ состояния ионов алюминия $\mathrm{Al}^{3+}$ в водных растворах. Простые соединения алюминия являются прекурсорами по всех процессах получения нанокомпозиционных материалов на основе оксидов алюминия. Состояние ионов $\mathbf{A l}^{3+}$ в водных растворах определяет механизм и структуру получаемых нанокомпозитов. Проведен анализ фазовых превращений в системах солей алюминия, гидратированных оксидов и оксидов. На основе этих данных определены основные режимы получения конечных материалов. Сделан анализ различных методов получения коллоидных растворов гидратированных оксидов алюминия как основного прекурсора при получении нанокомпозиционных материалов на основе оксидов алюминия. В качестве таких методов изучены 
процессы получения алюмозоля методом осаждения-пептизации. Также для синтеза алюмозолей рассмотрены методы ионного обмена и контролируемого гидролиза соединений алюминия. Для получения смешанных оксидных материалов, в системе $\mathrm{SiO}_{2}-\mathrm{Al}_{2} \mathrm{O}_{3}$, проведен анализ процессов взаимодействия кремне- и алюмозолей. Изучена возможность применения метода «гомогенное осаждение гидратированного оксида алюминия» для получения нанокомпозитов на основе оксида алюминия.

Ключевые слова: алюмозоль, аквакомплексы алюминия, гидроксокомплексы алюминия, алкоксиды алюминия, гидролиз соединений алюминия, гидратированные оксиды алюминия, бемит, псевдобемит, гидраргиллит, алюмо-кремнезоль, гомогенное осаждение.

DOI: dx.doi.org/10.15828/2075-8545-2018-10-1-37-62

МАШИНОЧИТАЕМАЯ ИНФОРМАЦИЯ о CC-ЛИЦЕНЗИИ В МЕТАДАННЫХ СТАТЬИ (НTML-КОД):

$<$ a rel="license" href="http://creativecommons.org/licenses/by/4.0/"><img alt="Лицензия Creative Commons" style="borderwidth:0" src="https://i.creativecommons.org/l/by/4.0/88x31.png" / ></a $><$ br / Произведение «<span xmlns:dct="http:// purl.org/dc/terms/" href="http://purl.org/dc/dcmitype/Text" property="dct:title" rel="dct:type">Растворимые соединения алюминия и нанокомпозитные материалы на их основе. Часть I </span>» созданное автором по имени <a xmlns:cc="http:// creativecommons.org/ns\#" href="Нанотех- нологии в строительстве. - 2018. - Том 10, № 1. - C. 37-62. - DOI: dx.doi. org/10.15828/2075-8545-2018-10-1-37-62" property="cc:attributionName" rel="cc:attributionURL">Кудрявцев П.Г., Кудрявцев Н.П., Фиговский О.Л. </a>, публикуется на условиях < a rel="license" href="http://creativecommons.org/licenses/ by/4.0/"> лицензии Creative Commons C указанием авторства 4.0 Всемирная $</ \mathrm{a}>$. $<$ br $/>$ Основано на произведении с $<\mathrm{a}$ xmlns:dct="http://purl.org/dc/terms/" href="http://nanobuild.ru/ru_RU/nanobuild-1-2018/" rel="dct:source">http:// nanobuild.ru/ru RU/nanobuild-1-2018/</a>. <br />Разрешения, выходящие за рамки данной лицензии, могут быть доступны на странице $<$ a xmlns:cc="http://creativecommons.org/ns\#" href="pgkudr89@gmail.com" rel="cc:morePermissions" $>$ pgku dr89@gmail.com $</ a>$.

\section{Введение}

Бурное развитие современной техники потребовало создания новых материалов, способных работать в экстремальных условиях внешних воздействий и, прежде всего, высоких температур. Среди всех известных термостойких веществ наиболее широким разнообразием химических свойств обладают оксиды металлов. В монографии [1] был сделан подробный анализ материалов, предназначенных для этих целей. Из большинства известных веществ можно выделить следующую группу 
оксидов: $\mathrm{SiO}_{2}, \mathrm{Al}_{2} \mathrm{O}_{3}, \mathrm{TiO}_{2}, \mathrm{MgO}$. Эти оксиды обладают высокой термостойкостью, химической устойчивостью, а также могут использоваться в виде индивидуальных компонентов высокотемпературных термостойких материалов. На основе данных оксидов могут быть созданы бинарные системы, также обладающие высокой тугоплавкостью: $\mathrm{SiO}_{2}-\mathrm{Al}_{2} \mathrm{O}_{3}$; $\mathrm{SiO}_{2}-\mathrm{MgO} ; \mathrm{SiO}_{2}-\mathrm{TiO}_{2} ; \mathrm{Al}_{2} \mathrm{O}_{3}-\mathrm{TiO}_{2} ; \mathrm{Al}_{2} \mathrm{O}_{3}-\mathrm{MgO} ; \mathrm{TiO}_{2}-\mathrm{MgO}$. Основные исследования в области оксидных огнеупоров могут быть направлены на разработку способов получения конкретных материалов, на основе оксидов и оксидных систем.

Нами уже была опубликована серия работ, посвященных новым материалам на силикатной основе $[121,122]$. Однако соединения кремния не обеспечивают необходимой термостойкости, особенно при температурах, превышающих $1500^{\circ} \mathrm{C}$. Одним из путей решения этой проблемы является создание материалов на основе оксидов алюминия. Настоящая работа посвящена изучению возможности применения золь-гель технологии для получения индивидуальных и композиционных материалов на основе оксидов алюминия.

\section{1. Состояние ионов алюминия $\left.A\right|^{3+}$ в водных растворах}

В водных растворах ионы $\mathrm{Al}^{3+}$ присутствуют в форме различных аква- и гидроксокомплексов. Для получения алюмозолей важное значение имеют термодинамические константы, описывающие взаимное превращение соответствующих аква- и гидроксокомплексов.

Определение координационного числа (КЧ) алюминия для его соединений в растворах - сложная задача, особенно в тех случаях, когда используются оксигидратные соединения. Химические сдвиги в спектрах ЯMP ${ }^{27} \mathrm{Al}$, представленные на рис. 1 , дают представление о строении металлорганических соединений типа $\left(\operatorname{RnAlX}_{3-\mathrm{n}}\right)_{\mathrm{m}}(m=1,2,3)$ и $\left[\mathrm{R}_{2} \mathrm{AlO}\left(\mathrm{CH}_{2}\right)_{2} \mathrm{Y}\right]_{2}\left(\mathrm{Y}-\mathrm{OR}^{\prime}, \mathrm{NR}_{2}^{\prime}\right)[1,2]$.

Сигналы $\eta^{5}$-циклопентадиенильных производных алюминия лежат в очень сильных полях, что указывает на положение атома металла в области магнитного экранирования ароматического кольца, но эти соединения характерны для низших степеней окисления алюминия 0 и +1 , и, по сути, стабилизируют их. Эти данные указывают на то, что низкие координационные числа для алюминия характерны в основном в соединениях с углеводородными лигандами. Кислородные же соединения 


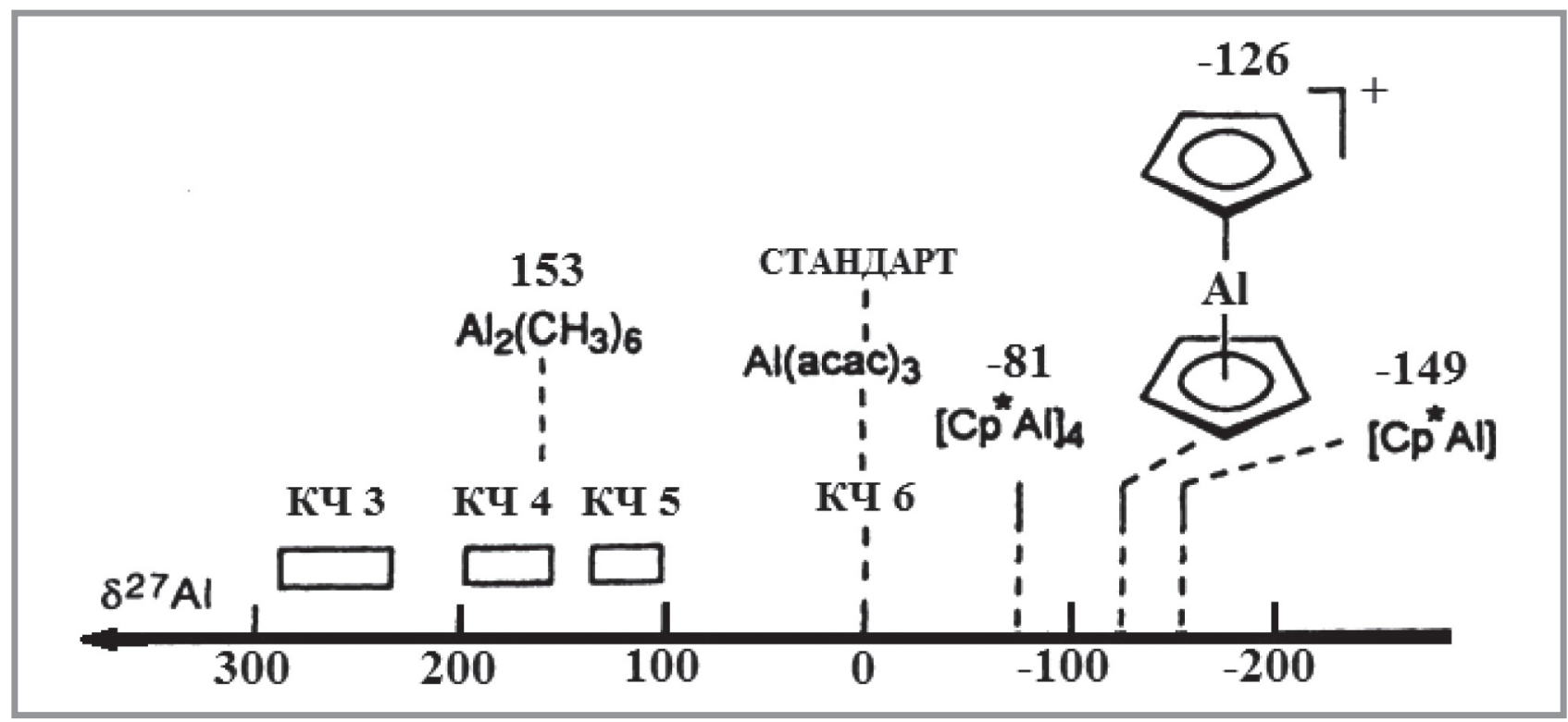

Puc. 1. Химические сдвиги в спектрах ЯМР ${ }^{27} \mathrm{Al}$ в различных соединениях, где алюминий находится в окружении с различными координационными числами [1, 2]

алюминия в основном проявляют координационное число 6 и формируют октаэдрическую координацию. Исключение составляют безводные алюминаты алюминия типа $\mathrm{MeAlO}_{2}$ (где $\mathrm{Me}$ - щелочной металл), получаемые из расплавов при высоких температурах, где возможна тетраэдрическая координация алюминия с к.ч. $=4$.

Промежуточная ситуация наблюдается у алкоксидов алюминия [3]. Исходя из общих представлений о строении алкоксипроизводных металлов, в работах $[4,5,6]$ показано, что молекулы алкоголятов алюминия представляют собой димеры (к.ч. $\mathrm{Al}=4$ ) или октамеры (к.ч. A1 = 6). Возникновение тетрамера является первым этапом в процессе старения. Второй этап заканчивается на образовании гексамера, а третий - октамера. Однако это не относится к производным вторичных и третичных спиртов. Процесс старения таких соединений сильно заторможен или вообще не имеет места, что является следствием стерических затруднений. Установлено, что в структуре $\mathrm{A} 1\left(\mathrm{OC}_{4} \mathrm{H}_{9} \text {-tert }\right)_{3}$ существуют два типа бутоксидов, соответствующих, по мнению авторов, концевым и мостиковым группам [7]. Так, $\mathrm{A} 1\left(\mathrm{OC}_{4} \mathrm{H}_{9} \text {-tert }\right)_{3}$ при температурах $-14 \div$ $+74^{\circ} \mathrm{C}$ существует в растворах в виде циклического димера, который не 
диссоциирует в диоксане или tert- $\mathrm{C}_{4} \mathrm{H}_{9} \mathrm{OH}$ даже при повышении температуры [8]. В работе [9] сделан вывод о тетраэдрической и октаэдрической координации атома алюминия в $i$-бутоксиде $\mathrm{A} 1\left(\mathrm{OC}_{3} \mathrm{H}_{7}-i\right)_{3}$, который сразу после растворения имел строение тетрамера, аналогичное предложенному в работах $[4,5,6]$. Нами были проведены квантовохимические расчеты строения этого соединения, которые подтвердили результаты указанных выше работ. Строение этого соединения представлено на рис. 2.

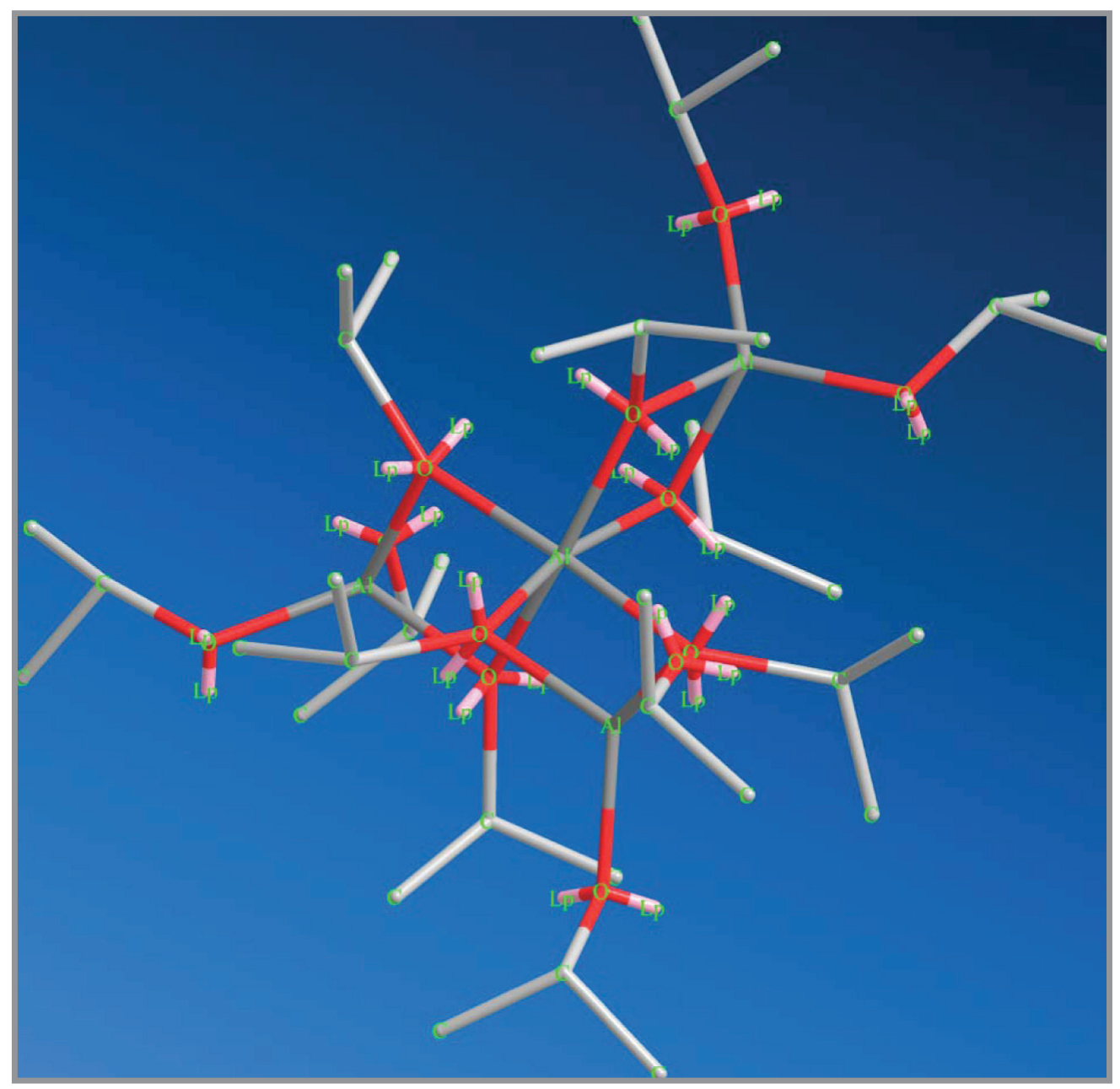

Рuc. 2. Часть структуры $i$-пропилата алюминия. Атомы водорода не изображены

При различных температурах в расплаве и растворах образуется циклический тример, который в дальнейшем переходит в тетрамер при кристаллизации. Медленное увеличение степени ассоциации свежепе- 
регнанного $\mathrm{A} 1\left(\mathrm{OC}_{3} \mathrm{H}_{7}-i\right)_{3}$ связано с олигомеризацией, за счет возрастания к.ч. A1 от 4 до 6. При этом внутримолекулярный обмен алкоксидных групп, отсутствующий у $\mathrm{A} 1\left(\mathrm{OC}_{4} \mathrm{H}_{9} \text {-tert }\right)_{3}$ даже при $74^{\circ} \mathrm{C}$, у изопропоксида происходит с заметной скоростью уже при $-13^{\circ} \mathrm{C}$, проходя через стадию переходного комплекса с к. ч. $\mathrm{A} 1=5$. Эти данные указывают на то, что алюминий с к. ч. $=4$ даже в алкоксидах присутствует только в условиях стерических затруднений при наличии объемных разветвленных алкоксидных групп и при использовании неполярных растворителей. Гидролиз же алкоксидов алюминия начинается с повышения их координационного числа, за счет дополнительной координации молекул воды атомами алюминия.

В работах $[1,2]$ представлены результаты расчетов свободной энергии Гиббса различных гидратных комплексов алюминия. Авторами получена следующая зависимость свободной энергии Гиббса от количества ОН-групп для гидроксидов элементов 3 группы периодической системы:

$$
\begin{aligned}
& \Delta G^{0}\left[\left(\mathrm{Me}\left(\mathrm{H}_{2} \mathrm{O}\right)_{6-n}(\mathrm{OH})_{n}\right)^{(3-n)+}\right]-\Delta G^{0}\left[\left(\mathrm{Me}\left(\mathrm{H}_{2} \mathrm{O}\right)_{6}\right)^{3+}\right]= \\
& =a_{0}\left(a_{1} n+a_{2} n^{2}\right),
\end{aligned}
$$

где $\Delta G^{0}$ - свободная энергия Гиббса, кДж/моль; $n$ - количество ОНгрупп; $\mathrm{a}_{0}=4,187 ; \mathrm{a}_{1}=-54,245 ; \mathrm{a}_{2}=1,02$.

Зная зависимость (1), можно определить свободную энергию Гиббса, которая, в частности, для ионов $\mathrm{Al}\left(\mathrm{H}_{2} \mathrm{O}\right)(\mathrm{OH})_{5}{ }^{2-}$ и $\mathrm{Al}(\mathrm{OH})_{6}{ }^{3-}$ составляет $-1498,06$ кДж/моль и $-1685,96$ кДж/моль соответственно. Используя полученные выше значения $\Delta G^{0}$ для ионов $\mathrm{Al}\left(\mathrm{H}_{2} \mathrm{O}\right)(\mathrm{OH})_{5}{ }^{2-}$ и $\mathrm{Al}(\mathrm{OH})_{6}{ }^{3-}$, были рассчитаны константы равновесия реакций образования соответствующих ионов. На основе этих данных рассчитана зависимость относительной доли гидроксокомплексов алюминия $\beta_{\mathrm{i}}$ от $\mathrm{pH}$ раствора, которая представлена на рис. 3 .

Анализ полученных данных показывает, какие гидроксокомплексы алюминия существуют при заданном значении рН. Так, например, при $\mathrm{pH}=12$ преимущественно существует только ионАl( $\mathrm{OH})_{6}{ }^{3-}$, а гидроксокомплекс $\mathrm{Al}\left(\mathrm{H}_{2} \mathrm{O}\right)_{3}(\mathrm{OH})_{3}$, проявляющий минимальную растворимость, будет существовать примерно при $\mathrm{pH}=6 \div 8$. Данные рис. 3 удобнее представить в виде шкалы рН (см. рис. 4). 


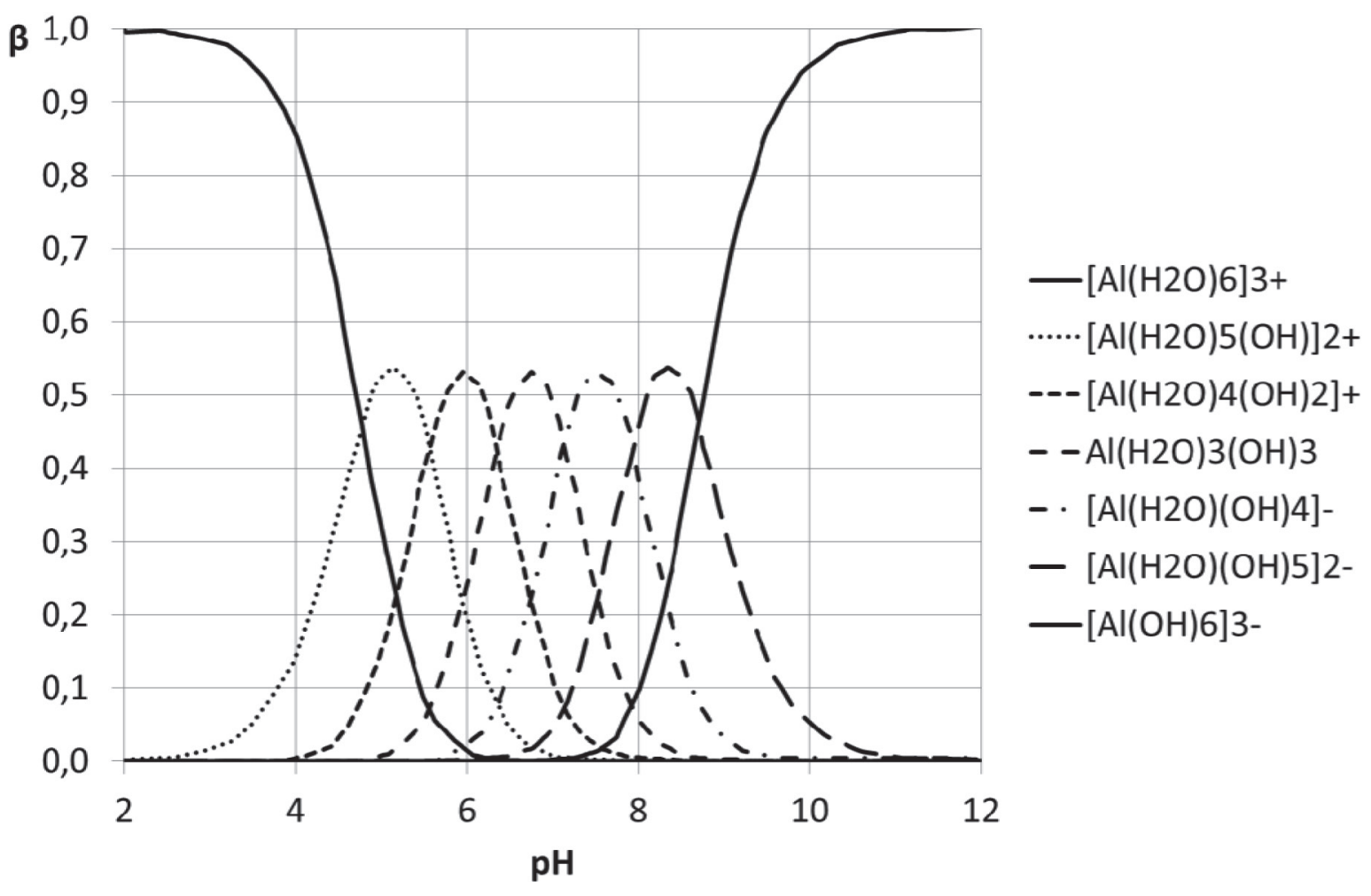

Рuc. 3. Зависимость относительной доли гидроксокомплексов алюминия $\boldsymbol{\beta}_{\mathrm{i}}$ в водном растворе от $\mathbf{p H}$

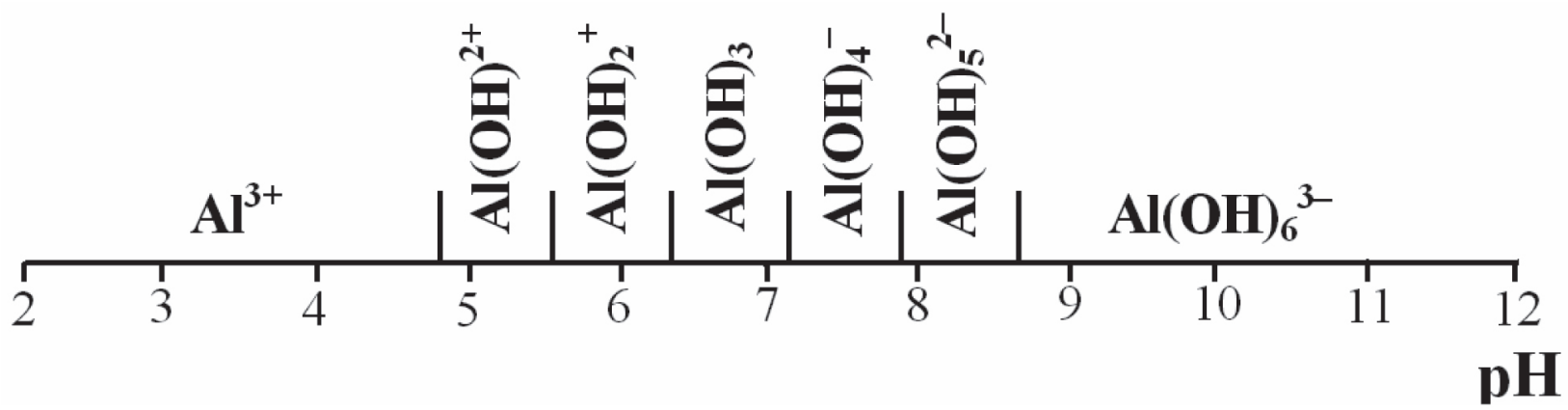

Pис. 4. Ионы вида $\mathrm{Al}\left(\mathrm{H}_{2} \mathrm{O}\right)_{6-\mathrm{n}}(\mathrm{OH})_{\mathrm{n}}{ }^{(3-\mathrm{n})-}$, существующие в растворе, в зависимости от рН среды 
Проведен расчет зависимости растворимости $\mathrm{Al}_{2} \mathrm{O}_{3}$ от $\mathrm{pH}$, для этого были рассмотрены следующие реакции взаимодействия $\mathrm{Al}_{2} \mathrm{O}_{3}$ с образованием различных ионов алюминия:

$$
\begin{aligned}
& \mathrm{Al}_{2} \mathrm{O}_{3}+6 \mathrm{H}^{+} \rightarrow 2 \mathrm{Al}\left(\mathrm{H}_{2} \mathrm{O}\right)_{6}^{3+}+3 \mathrm{H}_{2} \mathrm{O}, \\
& \mathrm{Al}_{2} \mathrm{O}_{3}+4 \mathrm{H}^{+} \rightarrow 2 \mathrm{Al}(\mathrm{OH})\left(\mathrm{H}_{2} \mathrm{O}\right)_{5}^{2+}+\mathrm{H}_{2} \mathrm{O}, \\
& \mathrm{Al}_{2} \mathrm{O}_{3}+2 \mathrm{H}^{+}+\mathrm{H}_{2} \mathrm{O} \rightarrow 2 \mathrm{Al}(\mathrm{OH})\left(\mathrm{H}_{2} \mathrm{O}\right)_{5}^{2+}, \\
& \mathrm{Al}_{2} \mathrm{O}_{3}+3 \mathrm{H}_{2} \mathrm{O} \rightarrow 2 \mathrm{Al}(\mathrm{OH})_{3}\left(\mathrm{H}_{2} \mathrm{O}\right)_{3}, \\
& \mathrm{Al}_{2} \mathrm{O}_{3}+5 \mathrm{H}_{2} \mathrm{O} \rightarrow 2 \mathrm{Al}(\mathrm{OH})_{4}\left(\mathrm{H}_{2} \mathrm{O}\right)_{2}^{-}+2 \mathrm{H}^{+}, \\
& \mathrm{Al}_{2} \mathrm{O}_{3}+7 \mathrm{H}_{2} \mathrm{O} \rightarrow 2 \mathrm{Al}(\mathrm{OH})_{5}\left(\mathrm{H}_{2} \mathrm{O}\right)^{2-}+4 \mathrm{H}^{+}, \\
& \mathrm{Al}_{2} \mathrm{O}_{3}+9 \mathrm{H}_{2} \mathrm{O} \rightarrow 2 \mathrm{Al}(\mathrm{OH})_{6}^{3-}+6 \mathrm{H}^{+} .
\end{aligned}
$$

Для каждой реакции рассчитана зависимость логарифма растворимости от рН и получена суммарная кривая. Данные зависимости представлены на рис. 5 .

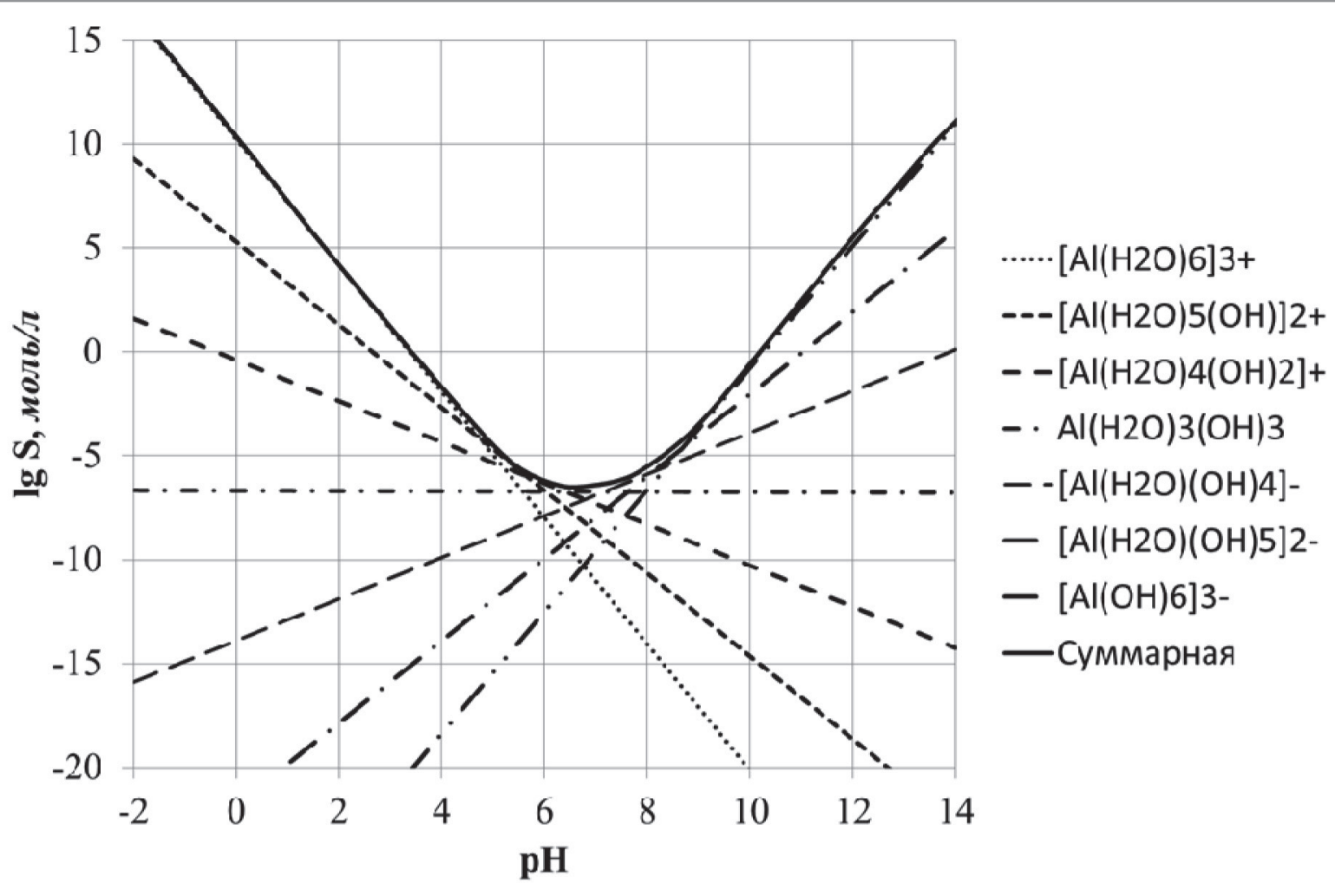

Рис. 5. Зависимость логарифма растворимости $\mathrm{Al}_{2} \mathrm{O}_{3}(\operatorname{lgS})$ от $\mathbf{p H}$ 
Полученные данные показывают, что при $\mathrm{pH}$ 6,7 наблюдается минимальная растворимость. Это значение $\mathrm{pH}$ соответствует точке нулевого заряда $-\mathrm{pH}_{\text {тнз }}$, что соответствует отсутствию заряда на поверхности частиц $\mathrm{Al}_{2} \mathrm{O}_{3}$.

При $\mathrm{pH}<\mathrm{pH}_{\text {тнз }}$ частицы $\mathrm{Al}_{2} \mathrm{O}_{3}$ имеют положительный заряд, а при $\mathrm{pH}>\mathrm{pH}_{\text {тнз }}$ - отрицательный заряд. Этот заряд обусловлен как диссоциацией ОН-групп, так и абсорбционным поглощением свободных $\mathrm{OH}-$ ионов. Максимальная скорость формирования твердой фазы гидратированного оксида алюминия, соответственно, будет наблюдаться в точке нулевого заряда ( $\left.\mathrm{pH}_{\text {тнз }}\right)$.

Полученные теоретические выводы в целом хорошо согласуются с экспериментальными данными. Таким образом, понижая $\mathrm{pH}$ раствора различными методами (в том числе электродиализом), можно добиться максимально полного осаждения гидроксида алюминия. Однако в некоторых источниках существуют различные данные о величине $\mathrm{pH}_{\text {тнз }}$ у гидратированных оксидов алюминия. Этот факт связан с различными методами его получения и, соответственно, с различной структурой его поверхности.

Гидроксид алюминия $\mathrm{Al}(\mathrm{OH})_{3}$ часто встречается в виде гелеобразного материала. В кристаллической форме его получают путем подачи $\mathrm{CO}_{2}$ в щелочной раствор алюмината щелочного металла при $80^{\circ} \mathrm{C}$. В природе гидроксид алюминия встречается чаще всего в виде гиббсита, а также и в виде других форм [10]. В литературе описаны различные модификации тригидроксида алюминия $\mathrm{Al}(\mathrm{OH})_{3}$. Из них наиболее распространенными являются: гиббсит (гидраргиллит), байерит и нордстрандит. Моногидроксид алюминия $\mathrm{AlOOH}$ известен в виде двух модификаций: диаспор и бемит [98]. Кроме этих кристаллических фаз в литературе встречаются сведения о ряде других гидроксидов алюминия. Однако эти формы недостаточно хорошо изучены. Поэтому остановимся на обсуждении кристаллического строения лишь гиббсита, байерита, нордстрандита, диаспора и бемита.

Для получения чистых фаз гидроксида алюминия рекомендуют нейтрализовать раствор алюмината натрия углекислым газом. Механизм этого процесса выражается следующей схемой [98]: 
$\mathrm{P}$ a

$\rightarrow$ А м о фная Ги д р о Оки с ь а люми ни я $\stackrel{20^{\circ} \mathrm{C}, p H<7}{\longrightarrow}$

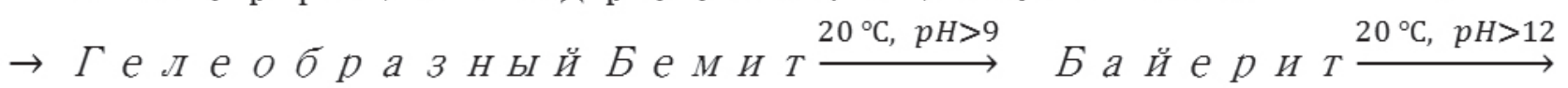

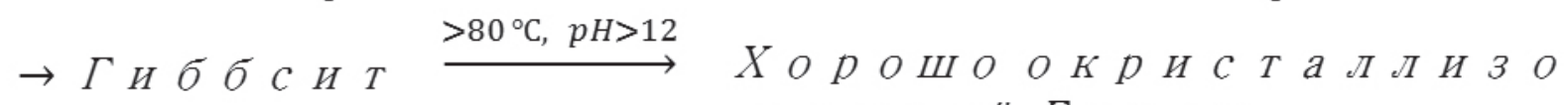
ванны й Бемит.

$\mathrm{AlO}(\mathrm{OH})$ получают в виде бемита при добавлении аммиака к кипящему раствору соли алюминия или из суспензии гиббсита в воде в автоклаве при $300^{\circ} \mathrm{C}[11]$.

В ряде работ [98, 119] было обнаружено, что природный и синтетический гиббсит всегда содержит ионы $\mathrm{Na}^{+}$в количестве $0,2 \div 0,3 \%$. Промывание кислотами не снижает количество натрия в твердой фазе. Хотя многие авторы утверждают, что без ионов щелочных металлов структура гиббсита вообще не может существовать, но это еще строго не доказано [98].

Кристаллические структуры гиббсита, байерита и нордстрандита схожи между собой и базируются на двойном слое гидроксильных ионов, упакованных приблизительно плотнейшим образом. Атомы алюминия находятся в октаэдрической координации, занимая, однако, лишь $2 / 3$ возможных позиций [117]. Строение кристаллической решетки гиббсита $\mathrm{Al}(\mathrm{OH})_{3}$ представлено на рис. 6.

Слои удерживаются вместе водородными связями, возникающими между ионами $\mathrm{OH}^{-}$. При этом каждая гидроксильная группа одного слоя располагается против $\mathrm{OH}^{-}$-группы следующего слоя. В результате получается моноклинная структура со следующими параметрами решетки: $a=862,4$ nл, $b=506,0$ nл $, c=972,0$ nл, $\beta=94^{\circ} 34^{\prime}, z=8$ [119].

В противоположность гиббситу для байерита не возникает вопрос о возможности стабилизации его структуры ионами щелочных металлов. В кристаллическом бемите $\mathrm{AlO}(\mathrm{OH}),-\mathrm{Al}-\mathrm{O}-\mathrm{Al}-\mathrm{O}-$ цепи соединяются с атомами кислорода ОН-групп соседней цепи. По данным [98], байерит имеет триклинную структуру. В результате такого искажения структуры получается, что минимальное расстояние О-О между атомами кислорода в двух соседних слоях в байерите больше (313 nл), чем в гиббсите (282 $n м)$.

Интересная закономерность, связывающая кислотно-основные свойства и структуру гидратированных оксидов в твердом состоянии, 


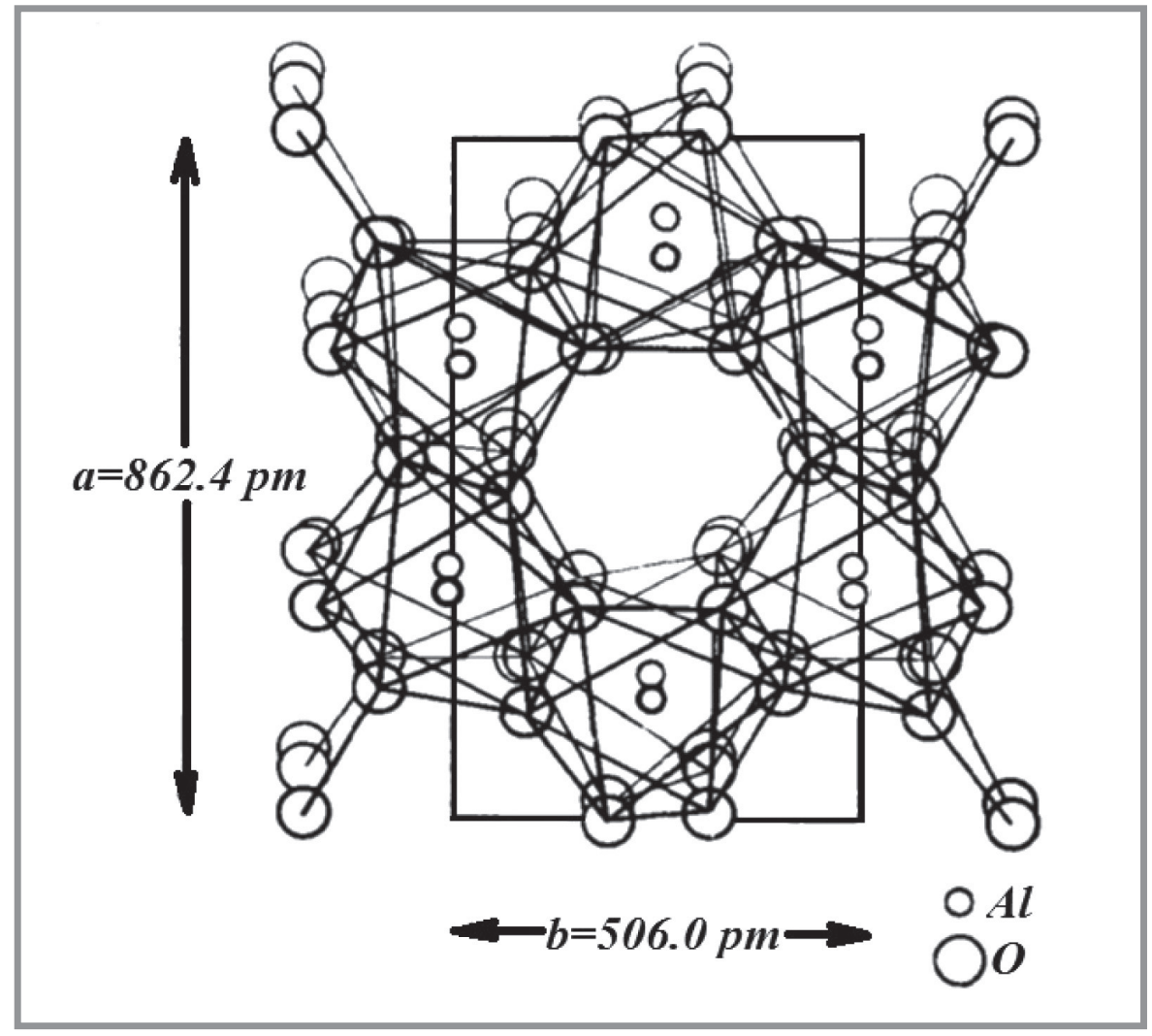

Рис. 6. Структура гиббсита $\mathrm{Al}(\mathrm{OH})_{3}$ : $a$ и $b$ - параметры элементарной ячейки

обнаружена Megaw H.D. [117]. При небольшом поляризующем влиянии катиона, $\mathrm{OH}^{-}$-группы упаковываются как нейтральные группы, и между центрами атомов кислорода сохраняется большое расстояние. В другом предельном случае, при значительном поляризующем влиянии катиона, возникает сильное притяжение между $\mathrm{OH}^{-}$-группами, в результате чего они приближаются друг к другу. Ниже, в табл. 1, приведены расстояния между атомами кислорода, иллюстрирующие этот эффект [117].

Таблица 1

Сравнение расстояния между атомами кислорода (nл) в структурах различных гидратированных оксидах

\begin{tabular}{|c|c|c|c|c|c|}
\hline $\mathrm{LiOH}$ & 361 & $\mathrm{Ca}(\mathrm{OH})_{2}$ & 336 & $\mathrm{Mg}(\mathrm{OH})_{2}$ & 322 \\
\hline $\mathrm{Zn}(\mathrm{OH})_{2}$ & 283 & $\mathrm{Al}(\mathrm{OH})_{3}$ & 281 & $\mathrm{~B}(\mathrm{OH})_{3}$ & 265 \\
\hline
\end{tabular}


Длина связи О-Н...О в гидратированных оксидах, обладающих кислотными свойствами, составляет в среднем 265 пл. Таким образом байерит должен сильнее проявлять основные свойства, чем гиббсит. Поэтому гидратированный оксид алюминия со структурой байерита будет легче подвергаться пептизации под действием кислот, а гиббсита - под действием щелочей.

Глинозем, $\mathrm{Al}_{2} \mathrm{O}_{3}$, получают путем дегидратации $\mathrm{AlO}(\mathrm{OH})$ или $\mathrm{Al}(\mathrm{OH})_{3}$, по меньшей мере, шести типов, из которых $\alpha-\mathrm{Al}_{2} \mathrm{O}_{3}$ (корунд) является формой, образуемой только при высокой температуре, $\alpha-\mathrm{Al}_{2} \mathrm{O}_{3}$ является неограниченно метастабильной при обычных температурах $[1,12] . \mathrm{B} \alpha-\mathrm{Al}_{2} \mathrm{O}_{3}$ ионы кислорода образуют гексагональный плотноупакованный массив, в котором ионы $\mathrm{Al}^{3+}$ распределены симметрично среди октаэдрических позиций [13]. Кристаллы гиббсита дают листовую структуру, основанную на двойном слое плотноупакованных гидроксильных ионов, при этом $\mathrm{Al}^{3+}$ располагается в двух третях октаэдрических позиций [14]. Реже форму $\mathrm{Al}(\mathrm{OH})_{3}$, нордстрандит, получают путем регулирования кристаллизации гелеобразного гидроксида добавлением хелатообразующего агента, этиленгликоля.

Существуют различные формы смешанных оксидов, содержащие алюминий и различные металлы. В таких смешанных оксидах ионы второго металла могут замещать $\mathrm{Al}^{3+}$ в октаэдрических позициях или занимать пустующие тетраэдрические позиции. Классическим примером такого смешанного оксида является шпинель $\mathrm{MgAl}_{2} \mathrm{O}_{4}$. Структура шпинели была исследована методами фотоэлектронной спектроскопии [15]. Колебательные и методы ЯМР твердого состояния также являются полезными для изучения структуры алюминатных соединений $[16,17,18]$.

Самым простым смешанным оксидом алюминия, содержащим щелочные металлы, является алюминат натрия $\mathrm{NaAlO}_{2}$. Его получают нагреванием $\mathrm{Al}_{2} \mathrm{O}_{3}$ с оксалатом натрия, карбонатом натрия или едким натром при $800 \div 1000^{\circ} \mathrm{C}$. Алюминат натрия образует белые кристаллы ромбической сингонии, параметры ячейки: $a=537 n л, b=521 n$ лм, $c=$ $707 n л, z=4$. Известно еще несколько соединений типа алюмината натрия в системе $\mathrm{Na}_{2} \mathrm{O}-\mathrm{Al}_{2} \mathrm{O}_{3}$. Так, $\mathrm{Na}_{5} \mathrm{AlO}_{4}$ образует ромбическую структуру: она содержит дискретную цепь тетраэдров $\mathrm{AlO}_{4}$, в которых $\mathrm{R}_{\mathrm{Al}-\mathrm{O}}=$ $176,1 \div 178,9$ пм. Триклинная $\mathrm{Na}_{7} \mathrm{Al}_{3} \mathrm{O}_{8}$ содержит кольцевую структуру, полученную из шести тетраэдрических $\mathrm{AlO}_{4}$ групп, связанных кислородными мостиками в бесконечной цепи, в то время как $\mathrm{Na}_{17} \mathrm{Al}_{5} \mathrm{O}_{16}$ име- 
ет дискретные цепи из пяти тетраэдров $\mathrm{AlO}_{4}$, распределенные по углам $[19,20,120]$. ЯМР-спектроскопия $\mathrm{Al}$ применительно к поликристаллическим алюминатам показывает характерные химические сдвиги для $\mathrm{AlO}_{4}, \mathrm{AlO}_{5}$ и $\mathrm{AlO}_{6}$ полиэдров [18]. Исследование алюмосиликатных растворов, осуществленное в работе [20], показало, что технологические процессы также обеспечивают формирование связей $\mathrm{Si}-\mathrm{O}-\mathrm{Al}$ по $\mathrm{AlO}_{4}$ группам. В структуре $\mathrm{Cs}_{2} \mathrm{Al}_{2} \mathrm{O}(\mathrm{OH})_{6}$ анион состоит в двух тетраэдров $\mathrm{AlO}_{4}$, разделенных одним атомом кислорода [21]. Комплексные анионы $\left[\mathrm{Al}_{4}(\mathrm{OH})_{16}\right]^{4-}$ и $\left[\mathrm{AlO}(\mathrm{OH})^{2-}\right]_{\infty}$ составлены из тетраэдрических групп, pacпределенных равномерно, их структуры были определены по дифракции рентгеновских лучей при исследовании алюминатов бария [22, 23]. Основной сульфат алюминия $\mathrm{Al}_{2}(\mathrm{OH})_{4}\left(\mathrm{SO}_{4}\right) \cdot 7 \mathrm{H}_{2} \mathrm{O}$ (алюминит) содержит комплексный катион $\left[\mathrm{Al}_{4}(\mathrm{OH})_{8}\left(\mathrm{OH}_{2}\right)_{6}\right]^{4+}$, построенный из четырех связанных ребрами октаэдров $\mathrm{AlO}_{6}$, которые образуют полимерные связи в цепи. Эти цепи соединены между собой ионами $\mathrm{SO}_{4}{ }^{2-}[24]$. Октаэдрическая координация алюминия в алюминатах кальция, которые являются основными компонентами портландцемента, была идентифицирована методами рентгеновской кристаллографии [25]. В другой области прикладной химии алюминия спектры ЯМР в условиях вращения под магическим углом были использованы, чтобы проследить гидратацию и дегидратацию позиций Al в ZSM-5 цеолитах. В этих соединениях также была зафиксирована октаэдрическая координация алюминия [26].

Гидратированный катион алюминия $\left[\mathrm{Al}\left(\mathrm{OH}_{2}\right)_{6}\right]^{3+}$ имеет октаэдрическую форму. Ниже представлены некоторые кристаллы, в которых он встречается (в скобках указано среднее расстояние $\mathrm{Al}-\mathrm{O}$ ): $\mathrm{NaAl}\left(\mathrm{SO}_{4}\right)_{2} \cdot \mathrm{H}_{2} \mathrm{O}(187,8$ nл); Меллайт (Mellite), также называемый «Meдовый камень», представляющий собой соль алюминия из меллитовой кислоты с химической формулой $\mathrm{Al}_{2} \mathrm{C}_{6}(\mathrm{COO})_{6} \cdot 16 \mathrm{H}_{2} \mathrm{O}$ [3] $(187,2$ nм); $\mathrm{AlCuCl}\left(\mathrm{SO}_{4}\right)_{2} \cdot 14 \mathrm{H}_{2} \mathrm{O}(187,8$ nл) [27]. Эти кристаллы были также исследованы методом нейтронной дифракции и методами ЯМР ${ }^{1} \mathrm{H}$, которые подтверждают наличие $\left[\mathrm{Al}\left(\mathrm{OH}_{2}\right)_{6}\right]^{3+}$ и разрешают локализацию атомов водорода молекул воды, находящихся в координационной сфере [28]. По данным комбинационного рассеяния, колебательные режимы иона $\left[\mathrm{Al}\left(\mathrm{OH}_{2}\right)_{6}\right]^{3+}$ в кристаллах квасцов были определены следующим образом: $v_{1}=542, v_{2}=473, v_{5}=347 \mathrm{~cm}^{-1}[29]$. В спектрах комбинационного рассеяния монокристаллов соли $\left[\mathrm{Al}\left(\mathrm{OH}_{2}\right)_{6}\right] \mathrm{Cl}_{3}$ имеет место колебательная мода $v_{\text {сим }}(\mathrm{Al}-\mathrm{O})$ на частоте 524 cm $^{-1}$ [30]. Алюминил-катионы $\mathrm{AlO}^{+}$, 
изолированные от $\mathrm{HF}$ растворов, в виде $\mathrm{BF}^{4-}$ или $\mathrm{SbF}^{6-}$ солей показывают v(Al-O) вблизи $650 \mathrm{~cm}^{-1}$ [31].

Полосы комбинационного рассеяния очень концентрированных растворов $\mathrm{Al}\left(\mathrm{NO}_{3}\right)_{3}$ согласуются с $\left[\mathrm{Al}\left(\mathrm{OH}_{2}\right)_{6}\right]^{3+}$ и $\mathrm{NO}_{3}{ }^{-}$в формах, разделенных растворителем ионных пар [32]. Протоны гидратной оболочки и массы воды можно различать с помощью ЯМР ${ }^{1} \mathrm{H}$. Сигналы ЯМР ${ }^{27} \mathrm{Al}$ позволяют отличить ионы $\left[\mathrm{Al}\left(\mathrm{OH}_{2}\right)_{6}\right]^{3+}$ от других видов, таких как $\left[\mathrm{Al}\left(\mathrm{OH}_{2}\right)_{5}\left(\mathrm{SO}_{4}\right)\right]^{+}$ в сульфатных растворах или $\left[\mathrm{Al}_{2}(\mathrm{OH})_{2}\left(\mathrm{OH}_{2}\right)_{8}\right]^{4+}$ и более высоко полимеризованных комплексов, которые образуются при старении водных растворов алюминатов [45]. Согласно данным, полученным методами комбинационного рассеяния [46] и ЯМР [36,47-56], сульфат и хлорид алюминия в растворе образуют катион $\left[\mathrm{Al}_{13} \mathrm{O}_{4}(\mathrm{OH})_{25}\left(\mathrm{OH}_{2}\right)_{11}\right]$. В присутствии $\mathrm{HCl}$ он разлагается на более мелкие частицы, но при добавлении щелочей могут быть сформированы частицы с более высокой молекулярной массой. В сильнощелочных растворах соединений алюминия преобладающими разновидностями являются моноядерные ионы $\left[\mathrm{Al}\left(\mathrm{H}_{2} \mathrm{O}\right)_{2}(\mathrm{OH})_{4}\right]^{-}$, $\left[\mathrm{Al}(\mathrm{OH})_{6}\right]^{-}$и биядерные ионы $\left[\mathrm{Al}_{2} \mathrm{O}(\mathrm{OH})_{6}\right]^{2-}[57-60]$.

УФ-спектры водных растворов $\mathrm{AlCl}_{3}, \mathrm{Al}\left(\mathrm{ClO}_{4}\right)_{3}, \mathrm{Al}\left(\mathrm{NO}_{3}\right)_{3}$ и $\mathrm{Al}_{2}\left(\mathrm{SO}_{4}\right)_{3}$ также подтверждают преобладание в их структуре катиона гекса-акваалюминия. Присутствие полосы поглощения при 240 нл обусловлено переносом заряда между внутренней координационной сферой и растворителем:

$$
\left[\mathrm{Al}\left(\mathrm{H}_{2} \mathrm{O}\right)_{6}\right]^{3+} \leftrightarrow\left[\mathrm{Al}(\mathrm{OH})\left(\mathrm{H}_{2} \mathrm{O}\right)_{5}\right]^{2+}+\mathrm{H}^{+} .
$$

Также было обнаружено, что хлоридные и перхлорат-анионы не замещают внутрисферные аква-группы в ионах гекса-аква-алюминия. При этом сульфат-анион, входя во внутреннюю координационную сферу, вызывал уменьшение этой линии, вплоть до полного ее исчезновения. Измерения эквивалентной проводимости показали, что сульфатный анион при концентрациях выше 0,50 М демонстрирует более сильное ионное спаривание, чем хлорид, нитрат и перхлорат. Этот эффект подтвердил вывод о том, что сульфат-анион может входить во внутреннюю координационную сферу $\mathrm{Al}^{3+}$ [61].

Для выяснения стереохимических ограничений, связанных со структурами гидратов алюминия, были проведены расчеты значения энергий с помощью метода молекулярных орбиталей, для комплексных ионов состава $\left[\mathrm{Al}\left(\mathrm{OH}_{2}\right)_{\mathrm{n}}\right]^{3+}(n=1 \div 7)$ [62] и гидроксокомплексов 
$\left[\mathrm{Al}(\mathrm{OH})_{4}\right]^{-},\left(\mathrm{Al}(\mathrm{OH})_{5}\right)^{2-}$ или $\left(\mathrm{Al}_{2}(\mathrm{OH})_{8}\right)^{2-}[63] . \mathrm{C}$ помощью метода молекулярных орбиталей также были выполнены расчеты для молекул $\mathrm{H}_{3} \mathrm{AlOH}_{2}$ и $\left(\mathrm{H}_{2} \mathrm{AlOH}\right)_{2}$ [64]. Подтверждения возможности существования подобных молекул не было получено. Однако малые молекулы такого рода иногда могут быть обнаружены с использованием методов матричной изоляции. Например, при взаимодействии атомов алюминия с молекулами $\mathrm{H}_{2} \mathrm{O}$ в экстремальных условиях происходит образование соединения типа $\mathrm{HAlOH}$, в то время как более тяжелые металлы III группы образуют $\mathrm{M} \cdot \mathrm{OH}_{2}$ аддукты [65].

\section{2. Фазовые превращения в системах, содержащих соли, гидратированные оксиды и оксиды алюминия}

В настоящем разделе приведены данные по равновесиям в системах «алюминий-вода». Эти измерения получены при температуре $25^{\circ} \mathrm{C}$ и представлены в виде уравнений и диаграммы Пурбе [66] (рис. 7).

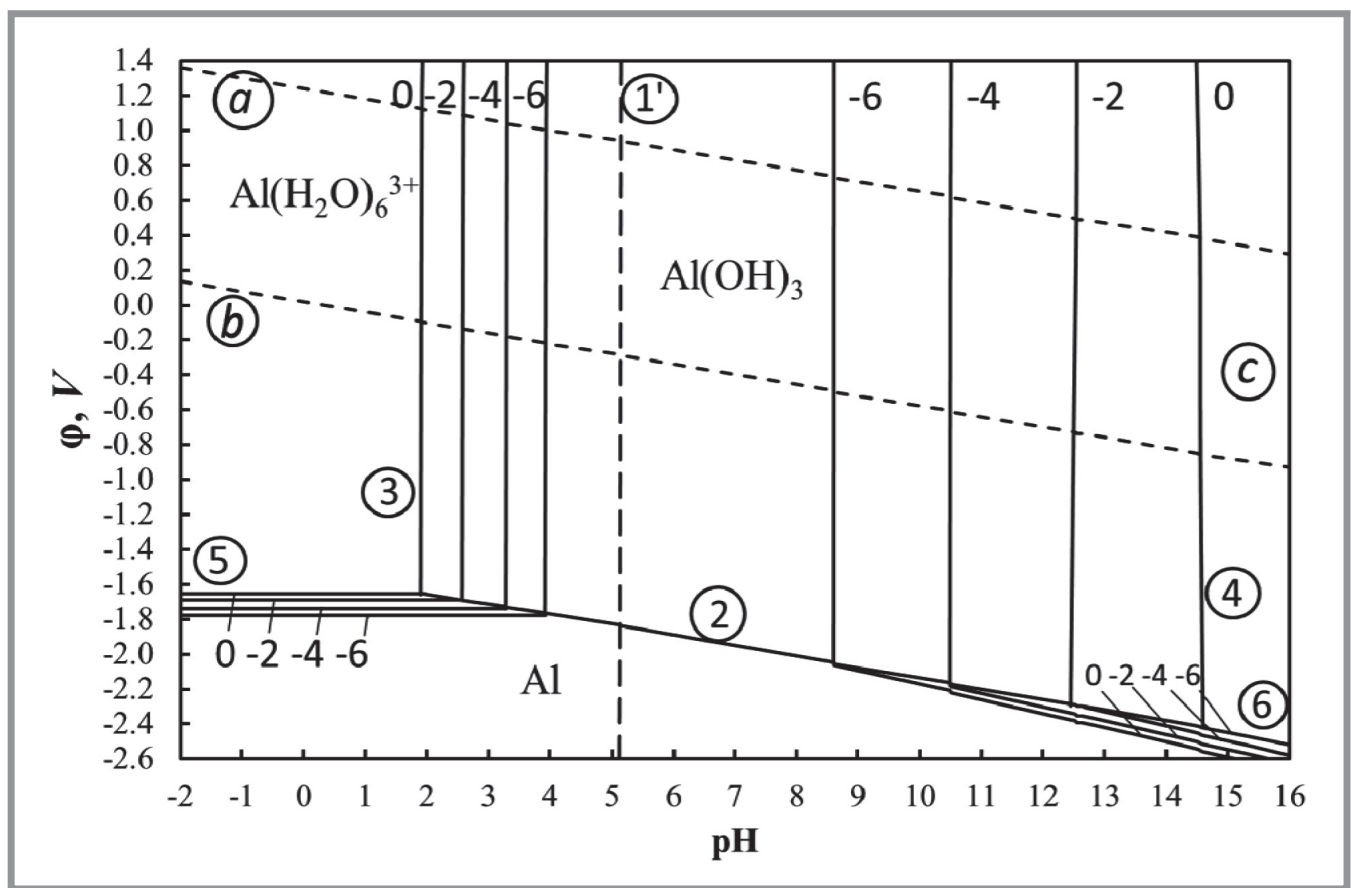

Рuc. 7. Диаграмма $\varphi$-рН для системы «алюминий-вода» при $25^{\circ} \mathrm{C}$ :

$a, b$ - две основные линии диаграммы состояния воды; $c$ - область образования анионов $\left[\mathrm{Al}\left(\mathrm{H}_{2} \mathrm{O}\right)_{2}(\mathrm{OH})_{4}\right]^{1-}$ и $\mathrm{Al}(\mathrm{OH})_{6}{ }^{3-} ; 1,2,3,4,5,6$ - линии равновесия, отвечающие номерам уравнений реакций, приведенных ниже в тексте.

Цифры у кривых соответствуют величине логарифма активности иона $\left(\lg a_{i}\right)$ 
Диаграммы Пурбе являются диаграммами состояния систем «элемент-вода» в координатах электродный потенциал - pH. Они представляют собой графики зависимости электродных потенциалов от $\mathrm{pH}$ раствора для реально устанавливающихся равновесий. Вертикальными линиями на диаграммах показаны значения $\mathrm{pH}$ образования соответствующих гидратов.

Ниже приведены уравнения реакций и формулы, которые показывают зависимость электродных потенциалов от активностей ионов и отношения активностей различных ионов, находящихся в равновесии с твердой фазой:

$$
\begin{aligned}
& \text { 1. }\left[\mathrm{Al}\left(\mathrm{H}_{2} \mathrm{O}\right)_{6}\right]^{3+}+2 \mathrm{H}_{2} \mathrm{O}=\left[\mathrm{Al}\left(\mathrm{H}_{2} \mathrm{O}\right)_{2}(\mathrm{OH})_{4}\right]^{1-}+4 \mathrm{H}^{+} \\
& \lg \frac{a_{\left[\mathrm{Al}\left(\mathrm{H}_{2} \mathrm{O}\right)_{2}(\mathrm{OH})_{4}\right]^{1-}}}{a_{\left[\mathrm{Al}\left(\mathrm{H}_{2} \mathrm{O}\right)_{6}\right]^{3+}}}=-20,30+4 \mathrm{pH} \text {; } \\
& \text { 1'. }\left[\mathrm{Al}\left(\mathrm{H}_{2} \mathrm{O}\right)_{6}\right]^{3+}+4 \mathrm{OH}^{-}=\left[\mathrm{Al}\left(\mathrm{H}_{2} \mathrm{O}\right)_{2}(\mathrm{OH})_{4}\right]^{1-}+4 \mathrm{H}_{2} \mathrm{O} \text {, } \\
& \mathrm{pH}=5,7 \text {; } \\
& \text { 2. } 2 \mathrm{Al}+3 \mathrm{H}_{2} \mathrm{O}=\mathrm{Al}_{2} \mathrm{O}_{3}+6 \mathrm{H}^{+}+6 e^{-} \text {, } \\
& \varphi=-1,550-0,0591 \mathrm{pH} \text {, } \\
& \mathrm{Al}+3 \mathrm{H}_{2} \mathrm{O}=\mathrm{Al}(\mathrm{OH})_{3}+3 \mathrm{H}^{+}+3 e^{-} \text {, } \\
& \varphi=-1,471-0,0591 \mathrm{pH} \text {; } \\
& \text { 3. } 2\left[\mathrm{Al}\left(\mathrm{H}_{2} \mathrm{O}\right)_{6}\right]^{3+}+3 \mathrm{H}_{2} \mathrm{O}=\mathrm{Al}_{2} \mathrm{O}_{3}+6 \mathrm{H}^{+}+6 \mathrm{H}_{2} \mathrm{O} \text {, } \\
& \lg a_{\left[\mathrm{Al}\left(\mathrm{H}_{2} \mathrm{O}\right)_{6}\right]^{3+}}=5,70-3 \mathrm{pH} \text {, } \\
& 2\left[\mathrm{Al}\left(\mathrm{H}_{2} \mathrm{O}\right)_{6}\right]^{3+}+3 \mathrm{H}_{2} \mathrm{O}=\mathrm{Al}(\mathrm{OH})_{3}+3 \mathrm{H}^{+}+6 \mathrm{H}_{2} \mathrm{O} \text {, } \\
& \lg a_{\left[\mathrm{Al}\left(\mathrm{H}_{2} \mathrm{O}\right)_{6}\right]^{3+}}=9,66-3 \mathrm{pH} \text {; } \\
& \text { 4. } \mathrm{Al}_{2} \mathrm{O}_{3}+9 \mathrm{H}_{2} \mathrm{O}=2\left[\mathrm{Al}\left(\mathrm{H}_{2} \mathrm{O}\right)_{2}(\mathrm{OH})_{4}\right]^{1-}+2 \mathrm{H}^{+} \text {, } \\
& \lg a_{\left[\mathrm{Al}\left(\mathrm{H}_{2} \mathrm{O}\right)_{2}(\mathrm{OH})_{4}\right]^{1-}}=-14,60+\mathrm{pH} \text {, } \\
& \mathrm{Al}(\mathrm{OH})_{3}+3 \mathrm{H}_{2} \mathrm{O}=\left[\mathrm{Al}\left(\mathrm{H}_{2} \mathrm{O}\right)_{2}(\mathrm{OH})_{4}\right]^{1-}+\mathrm{H}^{+} \text {, } \\
& \lg a_{\left[\mathrm{Al}\left(\mathrm{H}_{2} \mathrm{O}\right)_{2}(\mathrm{OH})_{4}\right]^{1-}}=-10,64+\mathrm{pH} \text {; } \\
& \text { 5. } \mathrm{Al}+6 \mathrm{H}_{2} \mathrm{O}=\left[\mathrm{Al}\left(\mathrm{H}_{2} \mathrm{O}\right)_{6}\right]^{3+}+3 e^{-} \text {, } \\
& \varphi=-1,663-0,0197 \lg a_{\left[\mathrm{Al}\left(\mathrm{H}_{2} \mathrm{O}\right)_{6}\right]^{3+},} \\
& \text { 6. } \mathrm{Al}+6 \mathrm{H}_{2} \mathrm{O}=\left[\mathrm{Al}\left(\mathrm{H}_{2} \mathrm{O}\right)_{2}(\mathrm{OH})_{4}\right]^{1-}+4 \mathrm{H}^{+}+3 e^{-} \text {, } \\
& \varphi=-1,663-0,0197 \lg a_{\left[\mathrm{Al}\left(\mathrm{H}_{2} \mathrm{O}\right)_{2}(\mathrm{OH})_{4}\right]^{1-}} \text {. }
\end{aligned}
$$


Электродные потенциалы ( $\varphi$ ) выражены по водородной шкале. Диаграммы состоят из областей, разграниченных между собой кривыми равновесия. В случае жидких фаз положение границы зависит от активности не только ионов водорода, но и других ионов, участвующих в установлении равновесия в растворе. Поэтому в таких случаях вместо одной кривой на рис. 7 нанесено семейство кривых, каждая из которых отвечает определенной активности соответствующих ионов (при этом для каждой кривой указано значение логарифма активности $\left.\left(\lg a_{i}\right)\right)$. Пунктирные линии отвечают электрохимическим равновесиям воды с продуктами ее восстановления - водородом (линия $a$ ) - и окисления кислородом (линия $b$ ) - при давлении этих газов, равном 1 атм. Область, находящаяся между этими двумя линиями, является областью устойчивости воды.

Точкам, лежащим в той или иной области, отвечает одна термодинамически устойчивая фаза. Так, области, расположенной в левой нижней части диаграммы системы $\mathrm{Al}-\mathrm{H}_{2} \mathrm{O}$ (рис. 7), отвечает металлическая фаза; при $\mathrm{pH}$ и потенциалах, соответствующих этой области, металлический алюминий термодинамически устойчив и, следовательно, не подвержен окислению. Области в левой части диаграммы, расположенной выше, отвечает термодинамически устойчивое состояние алюминия в виде иона $\mathrm{Al}^{3+}$ в растворе. Металлический алюминий, находящийся в условиях, отвечающих точкам в этой области, термодинамически неустойчив, он будет окисляться с некоторой скоростью. Область, расположенная правее, соответствует оксиду алюминия. Алюминий, находящийся в условиях какой-нибудь точки этой области, также термодинамически неустойчив. В зависимости от прочности сцепления оксидной пленки с металлом алюминий будет либо окисляться, либо находиться в пассивном состоянии (покрыт пленкой). Наконец, области, расположенной в правой части диаграммы, отвечает состояние алюминия в виде ионов $\left[\mathrm{Al}\left(\mathrm{H}_{2} \mathrm{O}\right)_{2}(\mathrm{OH})_{4}\right]^{1-}$ и $\mathrm{Al}(\mathrm{OH})_{6}{ }^{3-}$ в растворе. В условиях, соответствующих точкам в этой области, алюминий будет окисляться, превращаясь в соответствующий алюминат.

Существует несколько различных модификаций гидратированного оксида алюминия. Наиболее широко используемой формой является псевдобемит. Псевдобемит является одной из самых подвижных форм гидратированных оксидов алюминия, с точки зрения ее взаимодействия с кислотами и щелочами. Основным способом полу- 
чения псевдобемита на действующих производствах является переосаждение гидроксида алюминия, которое заключается в растворении гидраргиллита в кислоте или щелочи с последующей нейтрализацией и выделением осадка - гидратированного геля (гидрогеля). Полученный гидратированный гель в определенных условиях старения при $\mathrm{pH} 7,5 \div 9,0$ и температуре $20 \div 70^{\circ} \mathrm{C}$ превращается в псевдобемит [67]. Процесс старения гидрогеля состоит в постепенном обезвоживании. При этом происходят образование мостиковых связей через гидроксогруппы, с участием свободных электронных пар кислорода. Эти процессы называются оляцией, а образующиеся группы называются оловыми группами $-\mathrm{O}$ Н. Реакцию образования оловых соединений из гидроксо- или аквакомплексов иногда называют оляцией, а процесс получения оксосоединений из гидроксо-, аква- или оловых соединений - оксоляцией [113]. Образованию оловых соединений (оляция) и превращению их в оксосоединения (оксоляция) способствуют повышение температуры и концентрации раствора, а также его длительное выдерживание. Обратные процессы превращения оловых соединений в мономерные ионы протекает очень медленно, превращение же оксогрупп в оловые почти невозможно [114].

Процессы оксоляции, с образованием мостиковых оксо-связей или оксо-групп происходят параллельно. Процесс старения завершается последующей за ним кристаллизацией, с изменением строения молекул по следующей схеме:

Гидратированные катионы

алюминия

$$
\begin{aligned}
& \left(\left[\mathrm{Al}\left(\mathrm{H}_{2} \mathrm{O}\right)_{6}\right]^{3+} ; \mathrm{Al}(\mathrm{OH})\left(\mathrm{H}_{2} \mathrm{O}\right)_{5}^{2+} ; \rightarrow \begin{array}{c}
\text { Свежеосажденный } \\
\text { аморфнный гель }
\end{array} \rightarrow \begin{array}{c}
\text { Псевдобемит } \\
\left(\left[\mathrm{Al}_{4} \mathrm{O}_{3}(\mathrm{OH})_{6}\right]_{n}\right)
\end{array}\right. \\
& \mathrm{Al}(\mathrm{OH})_{2}\left(\mathrm{H}_{2} \mathrm{O}\right)_{4}^{+} \text {; } \\
& \mathrm{Al}_{2}(\mathrm{OH})_{2}\left(\mathrm{H}_{2} \mathrm{O}\right)_{8}^{4+} \text {; } \\
& \mathrm{Al}_{13}(\mathrm{OH})_{24}\left(\mathrm{H}_{2} \mathrm{O}\right)_{12}^{7+} \\
& \left(\left[\mathrm{Al}_{4} \mathrm{O}_{2}(\mathrm{OH})_{8}\right]_{n}\right)
\end{aligned}
$$

При этом происходит изменение формы частиц:

Мицеллы
золя $\rightarrow \begin{gathered}\text { Аморфные образования } \\ \text { из частиц золя }\end{gathered} \rightarrow \begin{gathered}\text { Волокна (иголки) или } \\ \text { кристаллы размером } 3 \div 4 \mathrm{HM} .\end{gathered}$


Скорость перехода каждой ступени определяется величиной $\mathrm{pH}$ среды, температурой и временем [67]. Образование плевдобемита идет путем кристаллизации в объеме аморфных сферических частиц, основу которых составляют моно- и биядерные гидроксокомплексы алюминия, с последующим формированием волокон или иголок по механизму «ориентированного наращивания» [68]. Причем для начала кристаллизации достаточно, чтобы произошла дегидратация $20 \div 40 \%$ аморфного гидроксида, чем и объясняется фазовая неоднородность псевдобемита.

При старении доля гидроксосолей уменьшается, а содержание структурной воды снижается до $1,5 \div 1,7$ моля $\mathrm{H}_{2} \mathrm{O} /$ моль $\mathrm{Al}_{2} \mathrm{O}_{3}$. Наличие в псевдобемите смеси двух и более морфологических форм (волокнистого аморфного, тонкодисперсного, игольчатого) значительно усложняет, а иногда и искажает результаты по изучению формирования пористой структуры активного оксида алюминия.

Обсуждая строение гидратированных оксидов, нельзя оставить без внимания структуру соответствующих оксидов, поскольку они является конечным продуктом обезвоживания гидроксидов. При нагревании гидроксида, в результате протекания реакций дегидратации и разложения, в кристаллах псевдобемита формируется новая фаза $\left(\gamma-\mathrm{Al}_{2} \mathrm{O}_{3}\right)$ с иными физическими и кристаллографическими параметрами $[69,70]$.

Существует довольно много модификаций $\mathrm{Al}_{2} \mathrm{O}_{3}$, однако структуры всех оксидов алюминия основаны на более или менее плотноупакованной кислородной подрешетке с ионами $\mathrm{Al}^{3+}$ в октаэдрических или тетраэдрических позициях.

Выделяют три ряда форм $\mathrm{Al}_{2} \mathrm{O}_{3}$ [98]:

$\alpha$-ряд с гексагональными плотноупакованными решетками;

$\beta$-ряд с попеременно чередующимися плотноупакованными решетками двух типов;

$\gamma$-ряд с кубическими плотноупакованными решетками.

Единственным представителем $\alpha$-ряда является $\alpha-\mathrm{Al}_{2} \mathrm{O}_{3}-$ корунд. $\beta$-ряд состоит, прежде всего, из $\beta$-окисей алюминия, содержащих ионы щелочных и щелочноземельных металлов и продуктов разложения гиббсита ( $\chi$ и $\theta$ - окиси алюминия). В $\gamma$-ряд входят продукты разложения гидроокисей - байерита, нордстрандита и бемита. Образование той или иной формы сильно зависит от исходных продуктов и условий термической обработки [98]. 
Следует также заметить, что следы натрия способствуют образованию $\beta$-модификации, тогда как присутствие ионов $\mathrm{Li}^{+}$или $\mathrm{Mg}^{2+}$ стабилизирует $\chi$-окись алюминия. Устойчивость кислородной подрешетки в процессе дегидратации играет наиболее важную роль в образовании различных форм $\mathrm{Al}_{2} \mathrm{O}_{3}$. Это связано с тем, что при этом наблюдается перемещение катионов в решетке. В форме корунда атомы алюминия находятся только в октаэдрических позициях. При переходе от формы гидроксида к форме корунда система проходит через стадии, где некоторые атомы алюминия могут занимать тетраэдрические полости [98].

Важной характеристикой системы $\mathrm{Al}(\mathrm{OH})_{3}-\mathrm{H}_{2} \mathrm{O}$ является ее фазовая диаграмма, которая представлена на рис. 8. Для сравнения, на ней изображена линия равновесия жидкость-пар для воды.

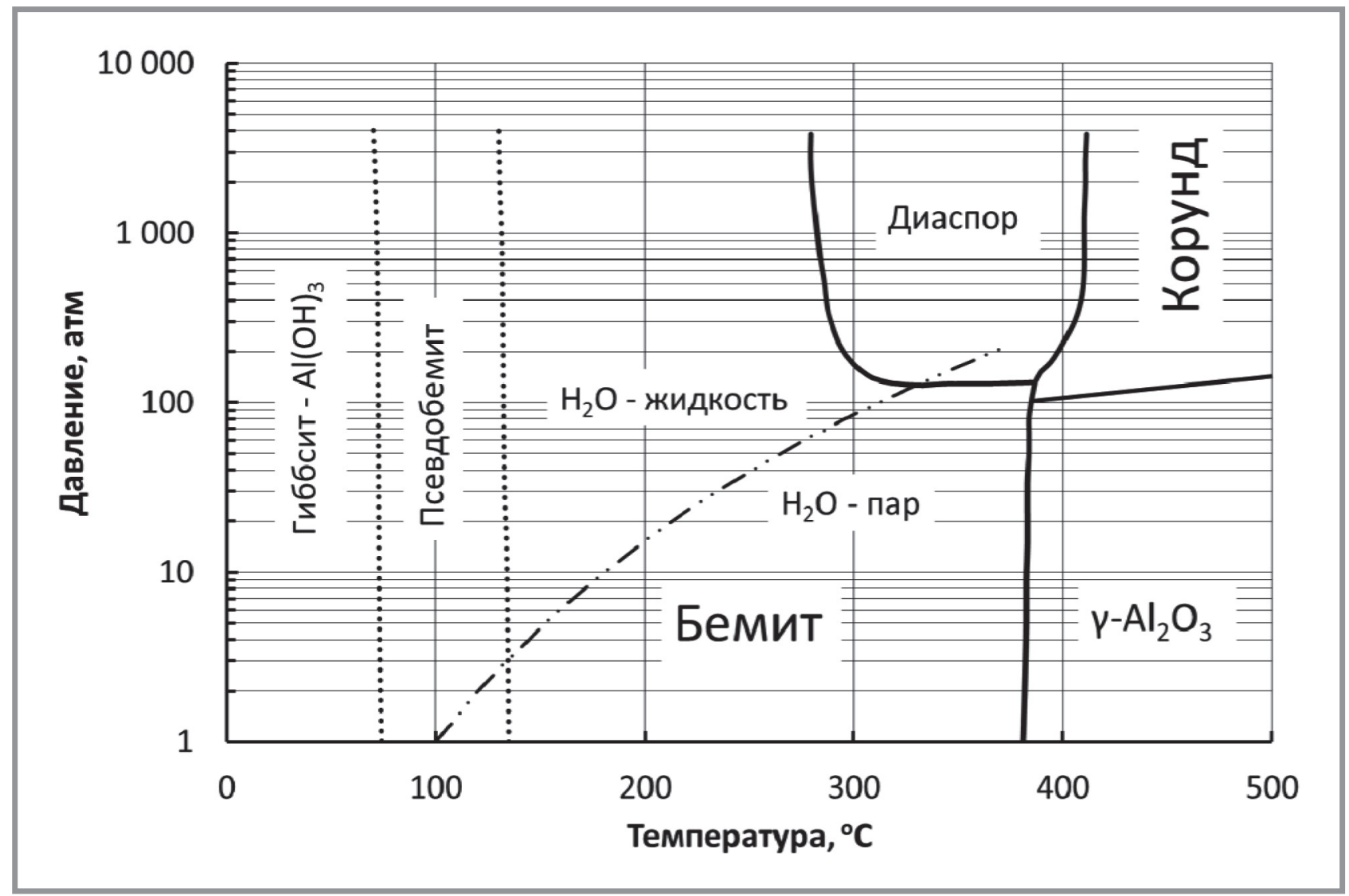

Рuc. 8. Фазовая диаграмма равновесия в системе $\mathrm{Al}(\mathrm{OH})_{3}-\mathrm{H}_{2} \mathrm{O}$.

Для сравнения на диаграмме штриховой линией проведена линия равновесия жидкость-пар для воды 
В работах $[69,70]$ были установлены три структурно-связанных стадии процесса дегидратации псевдобемита:

1) снятие искажения кристаллической решетки псевдобемита $\left(62 \div 283^{\circ} \mathrm{C}\right)$

2) частичное разложение структуры псевдобемита с образованием зародышей новой фазы $-\gamma-\mathrm{Al}_{2} \mathrm{O}_{3}\left(182 \div 362^{\circ} \mathrm{C}\right)$;

3) завершение кристаллизации $\gamma-\mathrm{Al}_{2} \mathrm{O}_{3}$ с последующим упорядочиванием его структуры $\left(342 \div 600^{\circ} \mathrm{C}\right)$.

Первая стадия включает потерю материалом адсорбционной воды и химическое взаимодействие между поверхностными гидроксильными группами с образованием мостиковых оксо-связей, сопровождающееся эндотермическим эффектом при температуре $110 \div 160^{\circ} \mathrm{C}$ :

$$
2 \mathrm{OH}^{-} \rightarrow \mathrm{O}^{2-}+\mathrm{H}_{2} \mathrm{O} \text {. }
$$

Эти процессы осложнены реакциями полимеризации оксисолей и некоторым упорядочиванием структуры гидроксида, что обуславливает экзотермический эффект при $250^{\circ} \mathrm{C}$ для гелеобразных образцов, а также удалением гидроксогрупп из межслоевого пространства структуры псевдобемита, в результате чего для гелеобразных образцов соотношение $\mathrm{H}_{2} \mathrm{O}: \mathrm{Al}$ достигает величины 0,75 .

На второй стадии наблюдается разложение - как отмечают авторы [55], оно происходит при сохранении октаэдрического окружения $\mathrm{Al}^{+3}$ ионами кислорода $-\mathrm{AlO}_{6}$. Температурный интервал этой стадии образования зародышей $\gamma-\mathrm{Al}_{2} \mathrm{O}_{3}$ определяется степенью кристалличности используемого псевдобемита. Для кристаллического образца вследствие разрушения алюмо-оксо-гидроксослоев возможно формирование структурных элементов фазы оксида алюминия, которые имеют четверную координацию атомов алюминия. При этом для гелеобразного образца обнаруживается лишь некоторое изменение общего характера, указывающее на деформацию структуры псевдобемита. Только при $345^{\circ} \mathrm{C}$ для гелеобразного псевдобемита обнаружена кристаллическая фаза оксида алюминия с несовершенной структурой [71]. При этом фиксируются две фазы: фаза $\gamma-\mathrm{Al}_{2} \mathrm{O}_{3}$, фаза псевдобемита.

На третьей стадии, при потере структурно-связанных гидроксильных групп $\left(445 \div 450^{\circ} \mathrm{C}\right)$, а также при упорядочении кристаллической структуры $\gamma-\mathrm{Al}_{2} \mathrm{O}_{3}\left(590 \div 600^{\circ} \mathrm{C}\right)$, протекают сильные процессы перекри- 
сталлизации и спекания, сопровождающиеся возрастанием размера кристаллов, снижением удельной поверхности и увеличением объема пор. При этом образуется $\gamma-\mathrm{Al}_{2} \mathrm{O}_{3}$, который является конечным продуктом термического разложения псевдобемита. Получаемый продукт может обладать различной пористостью, обусловленной строением исходных продуктов.

Характер пористости и величина удельной поверхности определяется морфологией псевдобемита. Наличие в смеси различных морфологических видов псевдобемита приводит, при термообработке, к хаотичности расположения кристаллитов с различной плотностью. Установленный механизм объясняет образование пор разнообразной формы и размера и различие в адсорбционной поверхности носителей и катализаторов [71].

Факт существования в оксиде алюминия алюмокислородных тетраэдров экспериментально установлен $[96,97,98]$ и сомнения не вызывает. Однако известно $[99,100]$, что алюмокислородный тетраэдр является неустойчивой структурой. В данном случае возможны два пути возникновения алюмокислородных тетраэдров. В момент образования новой структуры катион $\mathrm{Al}^{3+}$, оказавшийся на поверхности пакета бемитных слоев, после удаления гидроксильных групп может попасть как в октаэдрическую, так и в тетраэдрическую катионную вакансию. Кроме того, взаимное расположение структурных слоев таково, что, совершая переход из октаэдрической вакансии одного слоя в октаэдрическую вакансию другого слоя, катион алюминия обязательно должен перейти через тетраэдрическую вакансию, слой таких вакансий оказывается расположенным между основными структурными слоями. Таким образом, автор работы [72] предполагает, что алюмокислородные тетраэдры в низкотемпературных оксидах алюминия существуют потому, что катионы в них стабилизированы присутствием соседних катионов $\mathrm{Al}^{3+}$, находящихся в октаэдрах, которые окружают $\mathrm{AlO}_{4}$-тетраэдр (рис. 9).

Это положение катиона $\mathrm{Al}^{3+}$ не сбалансировано, и под действием электростатических сил отталкивания эти катионы стремятся перейти в соседний слой, в котором имеет место недостаток катионов. Аналогичная ситуация складывается и в приповерхностном слое катионов $\mathrm{Al}^{3+}$, в котором имеется избыток этих катионов.

Как известно, на поверхности кристалла бемита катионы алюминия отсутствуют, следовательно, свободные катионы также отсутствуют на 


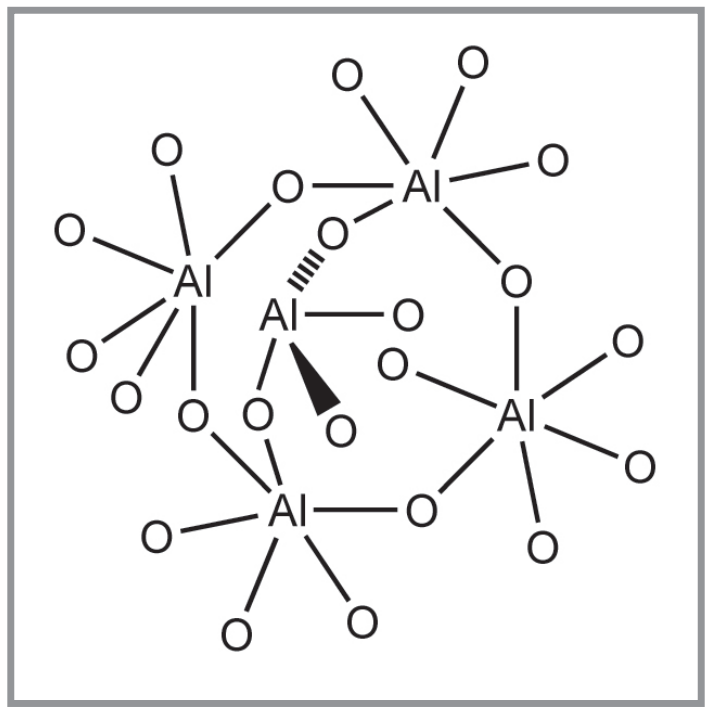

Puc. 9. Стерическая стабилизация $\mathbf{A l O}_{4}$-тетраэдров соседними $\mathrm{AlO}_{6}$-октаэдрами в объеме кристалла

поверхности оксида алюминия при его образовании. Из этого следует, что катионы алюминия, вышедшие из приповерхностного слоя в приповерхностные тетраэдрические катионные вакансии, не могут быть стабилизированы в них. Эти катионы выходят на поверхность первичного кристалла, этот переход обеспечивает баланс электростатических зарядов. Как было показано, такой переход катиона $\mathrm{Al}^{3+}$ из приповерхностного слоя катионной подрешетки на поверхность первичного кристалла совершается без преодоления энергетического барьера [101].

Важная особенность первичного кристалла $\gamma-\mathrm{Al}_{2} \mathrm{O}_{3}$ состоит в том, что его анионная подрешетка не является плотноупакованной [72]. Основными причинами нарушения плотности упаковки являются вкрапления остаточных гидроксильных групп, а также дефекты и дислокации, имеющиеся в материале. Эти гидроксильные группы представляют собой остатки от гидратированного оксида, который не полностью разрушился при разложении. Катионная структура определяется как промежуточное состояние между катионными подрешетками гидроксида-предшественника (в данном случае бемита) и корунда. Однако модификации оксида алюминия, переходные между бемитом и корундом, представляют собой многофакторные динамические системы. Увеличение температуры и/или времени прокаливания приводит к существенному, а часто необратимому изменению параметров этой системы. 
В связи с этим невозможно построить однозначную модель низкотемпературного оксида алюминия, точно соответствующую состоянию алюмокислородной системы на всем этапе существования низкотемпературной модификации оксида алюминия.

Части 2 и 3 статьи Кудрявцева П.Г., Кудрявцева Н.П., Фиговского О.Л. «Растворимые соединения алюлиния и нанокомпозитные материалы на их основе» читайте в нолерах 2/2018 и 3/2018 Интернет-журнала «Нанотехнологии в строительстве».

Список литературы к частял 1, 2 и 3 статьи Кудрявцева П.Г., Кудрявцева Н.П., Фиговского О.Л. "Растворимые соединения алюлиния и нанокомпозитные материалына их основе» будет опубликован также в нолере 3/2018 Интернет-журнала «Нанотехнологии в строительстве».

\section{УВАЖАЕМЫЕ КОЛЛЕГИ!}

ПРИ ИСПОЛЬЗОВАНИИ МАТЕРИАЛА ДАННОЙ СТАТЬИ

ПРОСИМ ДЕЛАТЬ БИБЛИОГРАФИЧЕСКУЮ ССЫЛКУ НА НЕЁ:

Кудрявиев П.Г., Кудрявиев Н.П., Фиговский О.Л. Растворимые соединения алюминия и нанокомпозитные материалы на их основе. Часть I // Нанотехнологии в строительстве. - 2018. - Том 10, № 1. - C. 37-62. - DOI: dx.doi. org/10.15828/2075-8545-2018-10-1-37-62.

\section{DeAr COlleagues!}

THE REFERENCE TO THIS PAPER HAS THE FOLLOWING CITATION FORMAT:

Kudryavtsev P.G., Kudryavtsev N.P., Figovsky O.L. The soluble aluminum compounds and nanocomposite materials based on them. Part I. Nanotehnologii v stroitel'stve $=$ Nanotechnologies in Construction. 2018, Vol. 10, no. 1, pp. 37-62. DOI: dx.doi.org/10.15828/2075-8545-2018-10-1-37-62. (In Russian). 